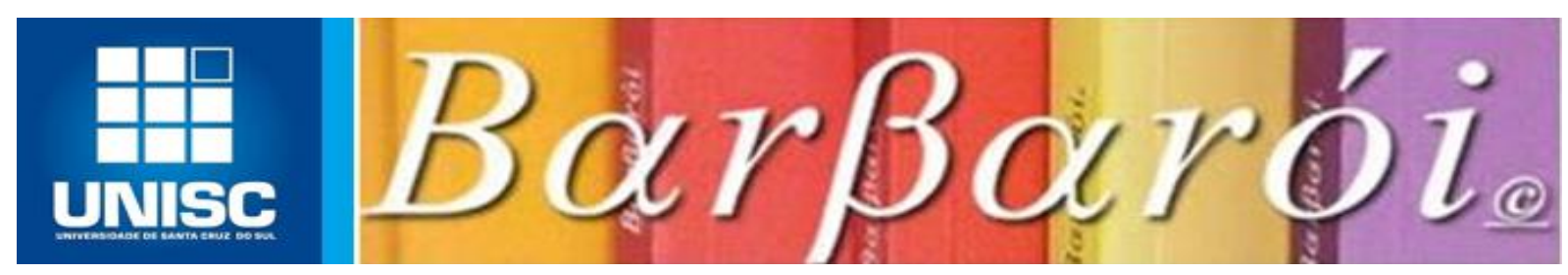

\title{
UM OLHAR À FAMÍLIA: RESSONÂNCIAS PSICOSSOCIAIS EM FAMILIARES QUE CONVIVEM COM UMA PESSOA EM SITUAÇÃO DE TRANSTORNO MENTAL
}

DOI: http://dx.doi.org/10.17058/barbaroi.v0i49.6617

\author{
$*$ \\ Maria Helena Santos Almeida \\ Universidade de Pernambuco - UPE - Brasil \\ Érika de Sousa Mendonça \\ Universidade de Pernambuco - UPE - Brasil

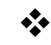

\section{Resumo:}

Os transtornos mentais caracterizam-se por alterações no comportamento, no humor e na maneira de pensar, podendo causar comprometimentos funcionais, provocando sofrimentos não só à pessoa que adoece, mas às pessoas com quem ela convive, em especial à família que se torna cuidadora principal. A pesquisa buscou compreender ressonâncias psicossociais em familiares que convivem e cuidam de um parente em situação de transtorno mental. Para tanto, realizou-se uma pesquisa qualitativa, que incluiu entrevistas semiestruturadas e rodas de conversa junto a familiares de usuários de um Centro de Atenção Psicossocial (CAPS), que frequentam o grupo de apoio familiar na instituição. A Análise de Conteúdo revelou três categorias de discussão, a saber: sentimentos da família diante do transtorno mental de seu familiar; a família na convivência e cuidado à pessoa em situação de transtorno mental; a assistência em saúde mental e a importância de cuidar também da família. Constatou-se a necessidade de atenção e assistência aos familiares que cuidam de uma pessoa em situação de transtorno mental, a partir da constatação dos sofrimentos, dificuldades e implicações em sua saúde física e mental frente ao contexto do adoecimento. Ainda, que os familiares contam com restritos espaços e redes de apoio e que, apesar de uma ação limitada no que se refere à integralidade e acolhimento ao familiar, o CAPS vem tendo sua atuação reconhecida positivamente pelos familiares de seus usuários.

Palavras-chave: Transtorno mental. Família. Cuidado.

\section{Introdução:}

O diagnóstico de uma doença geralmente causa tensionamentos na dinâmica familiar, e com o adoecer psíquico não é diferente. O aparecimento de transtorno mental em um membro da família pode desencadear uma variedade de sentimentos naqueles que, pela proximidade física e/ou afetiva passam a conviver com essa realidade. Os transtornos mentais se caracterizam principalmente por alterações no comportamento da pessoa acometida.

Segundo a Classificação Internacional de Transtornos Mentais e de Comportamento (CID-10), os transtornos mentais (TM) se classificam como doença com manifestação psicológica associada a algum comprometimento funcional resultante de disfunção biológica, social, psicológica, genética, física ou química. Podem ser 
classificados, ainda, como alterações do modo de pensar e/ou do humor associadas a uma angústia expressiva, produzindo prejuízos no desempenho global da pessoa no âmbito pessoal, social, ocupacional e familiar (SANTOS; SIQUEIRA, 2010, p.239).

A pessoa em situação de transtorno mental geralmente passa a agir de modo distinto de sua forma habitual, apresentando um comportamento por vezes divergente do "normal", tanto em relação ao seu comportamento anterior quanto em relação àquele convencionado pela sociedade. Segundo Fabris e Ykegaya (2011), há tempos busca-se explicações ao fenômeno da "loucura" e essas compreensões tiveram influências do contexto histórico em que foram criadas. As autoras, baseando-se na História da Loucura do filósofo francês Michel Foucault, apresentam concepções acerca da loucura ao longo da história, até chegar ao que hoje se denomina "doença mental".

De acordo com este percurso, segundo as autoras, a loucura durante a Idade Média foi considerada uma maldição divina, numa época em que explicações mítico-religiosas eram atribuídas à maioria dos fenômenos. No Renascimento (final da Idade Média até o século XVI), a loucura é tida como o "outro da razão", a trágica desrazão. Já na Idade Clássica (século XVII e XVIII), a figura do louco aparece como desviante da ordem vigente e se mistura à figura do mendigo e do delinquente. Apenas na Modernidade (final do século XVII ao século XIX), com Phillipe Pinel, médico francês, inaugura-se a percepção do louco como "doente mental".

Apesar das diferentes concepções da loucura, algo se repete na relação da sociedade com o louco, historicamente: a necessidade de excluí-lo dos espaços públicos de convivência. Nesse sentido tem-se, na época do Renascimento, o não-lugar dos loucos, expurgados das cidades nas embarcações, as chamadas naus dos loucos. Na Idade Clássica, vê-se o seu enclausuramento num movimento de separação do louco como desviante da moral, que deve ser internado nos Hospitais Gerais junto a outros "imorais" e deve ser punido. Na modernidade, assiste-se ao confinamento do agora "doente mental" nos manicômios, recebendo tratamento especializado, sob o olhar da psiquiatria (FABRIS e YKEGAYA, 2011).

Para Spadini e Souza (2006), no que se refere à família da pessoa em situação de transtorno mental, nos primórdios da psiquiatria, essa não acompanhava o familiar, permanecia distante do "tratamento", que era baseado na exclusão do doente mental e a família era, inclusive, considerada uma das causas da doença. No entanto, hoje essa mesma família é incluída no tratamento, sendo compreendida como elemento fundamental à recuperação da pessoa em situação de transtorno mental. Essa visão é compatível com o 
Movimento da Reforma Psiquiátrica, que se seguiu aos manicômios da Modernidade, e provocou mudanças de princípios em relação ao tratamento oferecido aos pacientes, bem como no posicionamento frente a seus familiares.

É na década de 1960 - em países como a Itália - e nos anos 1980 no Brasil, que começam a ser repensadas as práticas em saúde mental, em virtude das condições desumanas em que viviam as pessoas portadoras de transtorno psíquico, distantes de suas famílias e afastadas da sociedade (ROSA, 2003). A Reforma Psiquiátrica se apresenta, neste período, defendendo a substituição dos manicômios por outros dispositivos de tratamento contrários ao modelo asilar.

Neste contexto, a assistência às pessoas em situação de transtorno mental prevê a desinstitucionalização, ou seja, não mais a internação das mesmas em instituições como o hospital psiquiátrico, propondo novas maneiras de cuidar da pessoa com transtorno mental, sem retirá-la da convivência familiar e da comunidade. Entre esses novos dispositivos de tratamento, destacam-se os Centros de Atenção Psicossocial (CAPS).

\begin{abstract}
Os CAPS são instituições destinadas a acolher os pacientes com transtornos mentais, estimular sua integração social e familiar, apoiá-los em suas iniciativas de busca da autonomia, oferecer-lhes atendimento médico e psicológico. Sua característica principal é buscar integrá-los a um ambiente social e cultural concreto, designado como seu "território", o espaço da cidade onde se desenvolve a vida quotidiana de usuários e familiares. Os CAPS constituem a principal estratégia do processo de reforma psiquiátrica (BRASIL, 2004, p.9).
\end{abstract}

A partir da Reforma Psiquiátrica, a pessoa acometida por um transtorno mental deve ser acompanhada por dispositivos de cuidado como o CAPS, a quem cumpre oferecer atendimento diurno, em um ambiente acolhedor, que possa incluir pessoas em situação de crise, sendo essencial para o cumprimento de seu objetivo de atender casos de transtornos psíquicos graves, evitando a internação do sujeito. Algumas atividades terapêuticas desenvolvidas no CAPS são: a psicoterapia individual ou em grupo, oficinas terapêuticas, atividades artísticas, orientação e acompanhamento do uso de medicação, atendimento aos familiares (BRASIL, 2004). Um dos objetivos do CAPS é também promover a reintegração da pessoa em situação de transtorno mental ao seu ambiente familiar e à comunidade.

A família se torna a cuidadora de referência e será ela a responsável pelo bem-estar no dia-a-dia do familiar, atenta à sua medicação, no acompanhamento aos serviços de saúde, lidando com episódios de crise e comportamentos problemáticos do familiar, além de dar-lhe suporte social, afetivo e, às vezes, financeiro. Para a família, lidar com a situação de transtorno mental, com o impacto da mudança de comportamentos, alterações no humor ou no modo de pensar de um familiar, além do comprometimento funcional que um transtorno 
mental em geral pode trazer, pode deixá-la confusa, insegura, desestabilizada. Cavalheri (2010, p.52):

\begin{abstract}
O convívio com a doença, física ou psiquiátrica é muito difícil e desgastante para o grupo familiar, o que se agrava quando esta tende a ser de duração prolongada, apresenta recidivas de manifestações agudas e, principalmente, é vivida como incapacitante e estigmatizadora, que gera sobrecarga de ordem física, emocional e econômica, alterando toda a dinâmica familiar e comprometendo saúde, vida social, relação entre membros, lazer, disponibilidade financeira, rotina doméstica, desempenho profissional, e inúmeros outros aspectos do viver.
\end{abstract}

Do exposto, é possível que exista uma sobrecarga vivenciada pelos familiares na prestação de cuidados, bem como impactos em seu cotidiano com os novos encargos. Sentimentos de tristeza e desesperança frente ao contexto do transtorno mental de um familiar, além do cansaço físico, também podem fazer parte de suas experiências.

Segundo Melman (2006), a nossa sociedade não está preparada para cuidar e acolher as pessoas com transtorno mental passando a serem, estas últimas, vítimas de preconceitos e marginalização afetiva e social. Segundo o autor, o universo dos familiares das pessoas com transtorno mental é também uma realidade de preconceito e exclusão. Os familiares sentem-se paralisados e muitas vezes carentes de informações qualificadas, ficam perdidos e isolados, muitos obrigados a direcionarem a maior parte do seu tempo ao cuidado com o familiar doente.

Nesse sentido considera-se que a convivência com a pessoa em condição de transtorno mental pode gerar ressonâncias na dinâmica familiar, devido a mudanças na rotina da família por causa do transtorno e dos cuidados então requeridos. A família pode apresentar dificuldade em compreender e aceitar a doença do seu familiar, em lidar com mudanças de comportamentos do mesmo, seu comprometimento funcional, a dependência por cuidados e até apresentar sentimentos de tristeza, angústia, desesperança frente ao contexto de doença mental na família.

Levando-se em conta tal contexto, a pesquisa teve por objetivo compreender ressonâncias psicossociais em familiares que convivem com uma pessoa em situação de transtorno, buscando perceber sentidos que a família atribui a essa experiência; buscou-se também analisar redes de apoio a que a família recorre para cuidar do familiar em situação de transtorno mental e para cuidar de si mesma, e conhecer estratégias que desenvolve em seu cotidiano em prol de seu bem-estar e da dinâmica familiar. 


\title{
Metodologia:
}

Esta pesquisa teve caráter qualitativo e buscou compreender a experiência de familiares em conviver com uma pessoa em situação de transtorno mental. A pesquisa qualitativa, segundo Minayo (2008), está voltada a uma realidade que "não pode ou não deveria ser quantificada. Ou seja, ela trabalha com o universo dos significados, dos motivos, das aspirações, das crenças, dos valores e das atitudes" (p. 21).

Para alcançar os objetivos do estudo, desenvolveu-se uma pesquisa de campo junto a um Centro de Atenção Psicossocial (CAPS), com familiares de pessoas em situação de transtorno mental, cadastrados como usuários do referido CAPS, que participavam do Grupo Família que acontece semanalmente. Junto aos participantes desse estudo (sete familiares de diferentes usuários do CAPS), foram realizadas entrevistas semiestruturadas. A escolha desses familiares deu-se em função daqueles que participaram do Grupo Família do CAPS e se disponibilizaram a participar voluntariamente da pesquisa.

Para a coleta de dados realizou-se também uma roda de conversa com o tema "o cuidado de si", buscando contemplar os objetivos da pesquisa de compreender as estratégias construídas pela família para exercerem o cuidado de si e em prol do seu bem-estar e da dinâmica familiar. Segundo Méllo et al (2007, apud Figueirêdo e Queiroz,2012, p.2):

\begin{abstract}
As rodas de conversa priorizam discussões em torno de uma temática (selecionada de acordo com os objetivos da pesquisa) e, no processo dialógico, as pessoas podem apresentar suas elaborações, mesmo contraditórias, sendo que cada pessoa instiga a outra a falar, sendo possível se posicionar e ouvir o posicionamento do outro. Destarte, ao mesmo tempo em que as pessoas falam suas histórias, buscam compreendê-las por meio do exercício de pensar compartilhado, o qual possibilita a significação dos acontecimentos.
\end{abstract}

Visando a fidedignidade das falas dos entrevistados para posterior análise, as entrevistas, assim como as discussões que se estabeleceram na roda de conversa, foram gravadas com a autorização dos participantes. É importante salientar que esta pesquisa foi submetida e aprovada por um Comitê de Ética em Pesquisa e em respeito aos cuidados éticos, resguardou-se o anonimato dos participantes, substituindo seus nomes por outros fictícios ao longo da apresentação das falas, mantendo-se apenas o seu grau de parentesco em relação ao usuário do CAPS. Após a transcrição literal das entrevistas e da roda de conversa utilizou-se como técnica para análise de dados a Análise de Conteúdo, assim definida:

Um conjunto de técnicas de análise das comunicações visando obter por procedimentos sistemáticos e objectivos de descrição do conteúdo das mensagens indicadores (quantitativos ou não) que permitam a inferência de conhecimentos relativos às condições de produção/recepção (variáveis inferidas) destas mensagens (BARDIN, 1977, p.42). 
A partir de uma leitura do material coletado nas entrevistas construíram-se três categorias de discussão, a saber: sentimentos da família diante do transtorno mental de seu familiar; a família na convivência e cuidado à pessoa em situação de transtorno mental; a assistência em saúde mental e a importância do cuidado também da família. Sobre essas categorias de discussão, realizou-se a análises dos dados, buscando-se levantar reflexões acerca de ressonâncias psicossociais em familiares que convivem e cuidam de uma pessoa em situação de transtorno mental.

\section{1 - Sentimentos da família diante do transtorno mental de seu familiar:}

A descoberta do transtorno mental de um familiar pode despertar os mais diversos sentimentos naqueles que com ele convivem: medo, tristeza, incompreensão são alguns exemplos. O momento da descoberta do transtorno mental de um familiar se apresenta, em geral, como uma realidade inesperada para a família. Para Melman (2006), o adoecimento de um membro da família se configura como um forte abalo, podendo significar um momento de ruptura na trajetória de vida, que desestrutura as formas habituais de lidar com o cotidiano. Muitos familiares não sabem como enfrentar o problema e, procurando explicar o aparecimento da doença, não sabem como agir, sobrecarregando-se de dúvidas e conflitos.

Nas entrevistas com os familiares foi possível perceber que, em relação à descoberta da doença, os depoimentos referem-se principalmente ao drama vivido diante dos sinais e sintomas observados naquele que se encontra em situação de transtorno. Esses sinais são vividos com estranheza pelos familiares. Eis alguns de seus depoimentos:

\footnotetext{
Ele começou com umas coisa estranha dentro de casa, logo que eu me casei com ele, que eu não convivia, né? Eu namorava, não convivia, aí quando eu me casei com ele, quando penso que não (...) ele começou chorar, aboiando, umas coisa estranha, dizendo que a mãe dele tinha matado uma filha (...) (FLORA, esposa).

Depois de um ano que a gente tava morando junto, aí aparecia umas coisas diferente sabe? Uma coisa estranha diferente de quando eu namorei (...). Aí quando foi que ele arrumou um emprego trabalhava numa firma, aí lá na firma ele ficou piradinho, disse que tava me vendo num sei onde, me via num sei aonde, via as pessoas, e começou assim (...). Quando chegou em casa (...) é (...) muito agressivo, bem estranho mesmo, uma coisa que eu nunca vi né? (LUIZA, esposa)
}

Em geral os transtornos mentais causam considerável impacto no indivíduo, na família e até mesmo na sociedade em consequência dos sintomas, dos comportamentos que a pessoa apresenta e que são vistos como algo que foge ao padrão, causando estranheza e inquietação. Quadros com alucinações, delírios, fala desordenada, mudanças de humor, agressividade, não demoram a ser percebidos e interpretados como "loucura", algo que diverge do que é esperado pela sociedade e. Segundo Soares e Munari (2007, p. 358): 
Parece que o mais difícil para as famílias diante do acometimento de um membro da família por transtorno mental é a transformação da pessoa que eles antes conheciam. É como se o ente querido tivesse sido substituído por outro, desconectado dele mesmo, o que prejudica as relações, traz dificuldades de aprendizagem e de trabalho, colocando por terra seus objetivos na vida.

Ter um membro da família com transtorno mental pode significar, também, a falência da mesma em formar pessoas saudáveis. Os familiares em um primeiro momento podem negar tal realidade, não acreditando ser este o seu familiar, que parece outra pessoa. Como lidar com isso? O que fazer com esse familiar, que está estranho, que não é o mesmo? Os familiares vivenciam um momento de crise e luto, como ilustram as falas a seguir:

\footnotetext{
Quando foi com 11 meses de casada ela chegou em casa, chegou não, trouxeram ela, né? Ela doida varrida, dura, não falava, não comia, não bebia, não dormia, nem abrir a boca num abria, ela chegou nessa posição aqui: dura, dura e olhei pra ela assim e até eu temi né? Porque eu vi que não era a filha que eu criei (...) (LÚCIA, mãe)
}

Ela sempre gostou de dançar, gosta de conversar com muita gente, ela gosta... gostava né? De brincar, aí depois disso acabou. Ela sempre gostou de Roberta Miranda, arrumando a casa, cantando, sempre alegre, aí... Quando ela viu minha mãe ela disse não parece a Klécia! Não parece nada, porque mudou muito, mudou muito a vida dela. (JOANA, filha)

A descoberta da doença se apresenta, assim, como um momento que abala o equilíbrio familiar e até mesmo o modo como a família se vê. Ter um familiar em situação de transtorno mental pode abalar o ideal que a família tem de si, sua autoconfiança, acarretando sentimentos de impotência, culpa, vergonha, minando expectativas dos familiares em relação ao ente que adoeceu, a suas vidas, aos projetos futuros. Soares e Munari (2007, p. 358), elencam algumas das preocupações apresentadas pelas famílias: "comportamentos de isolamento, autodestruição, agressividade, falta de cooperação e maus hábitos de higiene, que podem gerar nos familiares ansiedade, raiva, culpa e medo, contribuindo para o sentimento de impotência frente à realidade inesperada”.

A família não está acostumada com os comportamentos apresentados pelo familiar, que muitas vezes inquietam, abalam o seu modo de vida, as relações entre os familiares. Os comportamentos desadaptativos, a agressividade, a falta de cooperação, a perda de controle do familiar, os comportamentos destrutivos, desgastam os relacionamentos, a convivência, a família fica impaciente com os sintomas do familiar, podendo causar estresse em toda a família, tal como revelam alguns entrevistados:

Ela fazia assim, ela dava cada baque na parede que eu não sei como a mão dela não doía, eu tenho uma menina e ela agora mora em São Paulo, e ela dizia que tava vendo a minha menina, tava vendo Márcia, ela procurava Márcia dentro do fogão, procurava Márcia debaixo das camas, Márcia dormindo ela avoava em cima de Márcia, um dia deu um tapa na boca de Márcia que o sangue voou (...). Ela cuspia a 
casa todinha, cuspia, ela via que eu já tinha passado pano, cuspia a casa, pegava papel de bolsa de mercado, rasgava uma por uma, uma por uma, uma por uma, deixava a casa completa (...) (CÍCERA, mãe).

Ela acabando tudo dentro de casa, pula de cima do primeiro andar pra cair em baixo, o menino ia chegando do trabalho, foi a sorte quando ela ia caindo, ele e o marido da minha sobrinha acudiram ela: Lara, o que é isso Lara?! Ela doida pra acabar tudo, se ela puder acabar o que tiver na frente dela ela acaba, viu? É tanta loucura, tanta besteira, tanta coisa que ela diz. Ela quer me matar! (LÚCIA, mãe)

Por esses depoimentos é possível imaginar os sofrimentos e as dificuldades vividas pelos familiares ao se depararem com a situação de transtorno mental de um de seus membros. Os familiares muitas vezes não conseguem entender o que está acontecendo e, carentes de informações, não sabem o que fazer, como intervir, sentem-se perdidos, fragilizados. Entre os entrevistados pôde-se considerar que em relação ao diagnóstico, a maioria dos familiares não sabe nomear o transtorno mental do seu familiar ou pouco sabe sobre esse transtorno, apesar do mesmo já estar em tratamento há meses. Como resposta à pergunta sobre o diagnóstico, alguns familiares afirmaram:

Ele é louco. É loucura mesmo. (FLORA, esposa)

Aí eu num sei, porque eu não pergunto pra ele e tudo mais (...). É um sofrimento, ele ta bem mais melhor, muito mais calmo, é que as pessoas que tem esse problema nunca fica bom né? (LUIZA, esposa).

A doença o médico falou que é escrizofrenia (...) é escrizrofenica, né? Que eu não sabia nem o que era isso escrizofrenia agora a gente vê falando na televisão e tudo né? (LÚCIA, mãe)

Podemos inferir que os familiares têm pouco ou nenhum conhecimento em relação ao transtorno mental que acomete seu parente, o que pode contribuir para o seu sentimento de desespero, incompreensão, diante do transtorno mental do seu parente, além do estigma: "Ele é louco", como se pode observar nas narrativas dos participantes do estudo. A desinformação aponta para o nível de desconhecimento desses familiares que têm na televisão, muitas vezes, o único acesso à informação, como atestam em suas narrativas.

É preciso considerar, ainda, que o público que é atendido no CAPS trata-se, em geral, de uma população que vive em condição de pobreza, cujo acesso à informação geralmente é restrito e o único esclarecimento que os familiares possuem sobre o diagnóstico do seu familiar é aquele que o médico dá, que na maior parte das vezes é insuficiente. Para Colvero, Ide e Rolim (2004), os familiares procurando entender o que acontece com os seus familiares, reafirmam a dificuldade de conviver com uma pessoa em situação de transtorno mental, como se nada afinal fizesse sentido ou conseguisse amenizar essas experiências. 
A doença mental e todas as situações que acarreta, abalam a autoestima e esperanças dos familiares. O transtorno mental aparece como algo que familiares não conseguem compreender, fazendo-os questionarem-se quanto aos motivos daquele transtorno, inquirindose onde erraram para que isso acontecesse. Esses questionamentos aparecem acompanhados por sentimentos como: incompreensão, inconformismo, tristeza, desesperança. Alguns depoimentos vão nesta direção:

Eu me senti nada mais na vida, pra mim se fosse eu que tivesse no lugar dela ali eu achava melhor de que vê minha filha naquela situação né? Morri, me acabei, fiquei doida chorando e pedindo a Deus que fizesse com que eu entendesse o que foi que deu naquela criatura, né? Que eu não sei o porquê daquilo ali, eu não sei né? $\mathrm{O}$ porque daquela coisa tão triste, eu não via minha filha na minha vista eu via outra pessoa diferente né? Parecia uma fera mais brava do mundo, aí eu fiquei doida, viu? Eu e toda família. (LÚCIA, mãe)

Triste, mulher! Ave Maria! Eu chorava o dia todinho, triste que eu não tinha sossego, porque eu dormia mais fora, mais na casa da minha família, quando eu chegava bem cedo, pra ela foi o cão que entrava dentro de casa! (CÍCERA, mãe)

A partir da situação de transtorno mental, a família vivencia processos de mudanças, que tem ressonâncias em todos os membros. Segundo Borba et. al (2011, p. 447): "A doença consiste em evento adverso e inesperado que desorganiza a maneira de ser da família, exige nova organização e adaptação à nova situação". Pereira e Pereira (2003, apud BORBA, SCHWARTZ e KANTORSKI, 2008, p. 589) compartilham reflexões similares:

A presença do sofrimento mental no ambiente familiar provoca mudanças nas rotinas, hábitos e costumes da família. Com o impacto do diagnóstico, a necessidade de adaptação à nova situação, o estigma social, a dependência e as implicações da cronicidade do quadro clínico podem produzir sobrecarga, conflitos, sentimentos de incredulidade, perda do controle e medo, visto que a família vivencia uma situação de desgaste.

A demanda por um cuidado contínuo do familiar adoecido, lidar com os episódios de crise, limitações, mudanças de comportamento, além das tarefas e atribuições que o familiar já possui, todos esses fatores tendem a gerar sobrecarrega. Para Koga e Furegato (2002) o familiar se desgasta em conviver com a pessoa portadora de transtorno mental, acarretando sobrecarga física e emocional, privando-se da sua própria saúde para poder prestar assistência adequada ao doente.

Com o novo modelo de cuidados não mais centrado nos hospitais psiquiátricos e no processo de exclusão da pessoa em situação de transtorno mental, mas na reinserção do mesmo na sociedade, os familiares se deparam com a realidade de cuidar do familiar em situação de transtorno mental que agora reside em casa. Na maioria das vezes os familiares somente contam com o apoio do CAPS e se tornam os principais responsáveis pelo cuidado 
ao familiar. No entanto, pode-se indagar: será que a família está sendo preparada para ser a principal responsável pelo cuidado a uma pessoa em situação de transtorno mental? Será que ela possui recursos - sejam financeiros, sociais, psicológicos e até físicos - para cuidar desse familiar de maneira que possibilite o seu bem-estar e o da família?

A experiência dos familiares mostra dificuldades em conviver e cuidar e revela que essa é uma realidade difícil e desgastante, que requer renúncias e dedicação, além de se referir às responsabilidades que precisaram assumir quando a condição do familiar lhe é incapacitante. Eis algumas dessas falas:

Tem que ter paciência e cuidar, é ajudar quando tá doente, tem que falar, conversar com ele, dizer vá pra um canto, ajudar, onde a gente puder levar e fazer assim coisa que ele gosta, pra ele se distrair né? (LUIZA, esposa)

Eu realmente fui ficar uma pessoa de dedicação pra ele, dentro de casa né? E arrumava um trabalho, não podia trabalhar que não ia deixar ele sozinho, que ele ficava louco dentro de casa, botava fogo na casa, já tinha que deixar aquele trabalho pra vim tomar de conta dele. (FLORA, esposa)

Tem horas, momentos que ela não quer fazer as coisas, agora mesmo ela ta com dengue. O peso da casa, doméstico, tá todo comigo! Mas pra tudo sempre é mias eu do que ela, pra tudo, a responsabilidade de casa, feira, mercado, armazém, essas coisas é tudo minha (...) (LÍDIA, filha)

Pode-se considerar que, repentinamente, familiares se veem com o encargo de cuidar de alguém mesmo sem estar preparado. Nesse sentido, filhos acabam por cuidar dos pais, assumir responsabilidades que seriam deles quando o mesmo se encontra em situação de transtorno, cônjuges precisam renunciar aos empregos e a uma vida social para cuidar do esposo ou esposa e aquele que seria uma ajudante no cuidado com os filhos e a casa acaba por ser alguém que também passa a demandar cuidados em razão do transtorno. A família se modifica, a situação de transtorno mental de um familiar exige novas adaptações, impactando, assim, não somente a trajetória da pessoa que adoece, mas também da família.

\section{2 - A família na convivência e cuidado à pessoa em situação de transtorno mental:}

Os impactos na família que passa a conviver com a pessoa em situação de transtorno mental mostram-se, assim, de várias ordens: afetivo, físico, psíquico, social, financeiro. A família precisa se readaptar para atender às demandas que lhe são requisitadas e manter o equilíbrio. Os parentes que assumem as principais responsabilidades tornam-se cuidadores do outro, mas, por vezes, descuidam-se de si mesmos. Essa situação se agrava visto que a situação de transtorno mental geralmente não é algo passageiro, mas tem duração prolongada, exigindo adaptações permanentes. Segundo Navarini e Hirdes (2008, p.683): 
Essa sobrecarga familiar é sentida não somente nos aspectos emocional e físico, mas também nos encargos econômicos. Em geral, os pacientes psiquiátricos apresentam grandes obstáculos para produzir economicamente, o que implica uma situação de dependência da família.

Em relação à convivência e o cuidado com a pessoa em situação de transtorno mental, os familiares entrevistados apontaram dificuldades em compreender os comportamentos do familiar, falta de preparo para lidar com as crises, com os comportamentos agressivos, com o imprevisível do comportamento, com a falta de cooperação do familiar, o que acaba gerando nervosismo, irritabilidade, tristeza. Os mesmos relatam que a convivência é difícil e que é preciso ter paciência, como se pode observar nas falas a seguir:

É muito difícil porque a gente não entende a cabeça desse povo né? Não entende o que é que eles tem no pensamento, o que é que eles vão fazer, a gente não sabe, a gente tenta lidar com eles assim mesmo, tem que ter paciência, porque se a gente não tiver paciência, minha filha, enlouquece! Fica doente também! Tem que ter paciência. (MARIA, esposa)

É muito difícil, muito difícil, mas... Deus amostra força pra pessoa lutar e tudo, porque tem hora que você termina quase igualzinha a ele, tem hora que eu fico nervosa dentro de casa com ele, com esses problemas dentro de casa né? Que ele fica dentro de casa, ele faz uma bagunça, e se você não tiver perto dele, ele toca fogo nas coisas, agora assim né, ele passa mais de ano assim acompanhando o CAPS, não adoece, mas também quando vem uma crise é pra ele passar dois anos, na crise dentro de casa, eu sofro muito com ele. (FLORA, esposa)

A família reflete que as dificuldades e sofrimentos com a convivência e cuidado à pessoa em situação de transtorno mental acabam por adoecer também os familiares, que buscam saídas para lidar com essa realidade. Uma das saídas apontadas é a paciência, mas pode-se indagar: a paciência é o suficiente? Até onde esses familiares conseguem suportar uma convivência tantas vezes desgastante e permeada de conflitos? Não ficaria a saúde dos familiares também comprometida? Os sujeitos afirmam que estão ficando "iguaizinhos" ao seu familiar em situação de transtorno, em um contexto que se mostra bastante desgastante. Para Soares e Munari (2007, p. 360):

A convivência em ambiente de constante estresse, trauma, perdas, tristeza e cansaço, pode levar pessoas da família a apresentar "desordens paralelas" chamadas de traumas secundários como negação, minimização, forte tolerância a comportamentos inapropriados, confusão, dúvida, culpa, depressão e problemas físicos e emocionais.

O contato constante com o familiar em situação de transtorno mental, os conflitos decorrentes desse convívio, as situações de estresse, podem acarretar desordens emocionais nos familiares afetando diretamente a sua saúde psíquica, podendo-se considerar alta a probabilidade de também desenvolverem problemas de saúde em decorrência desse convívio. 
A pessoa em situação de transtorno mental tende a demandar dos familiares uma atenção contínua. Cuidar desse familiar, dar apoio, levar ao médico, desempenhar funções que a pessoa já não desempenha, além de dar-lhe suporte econômico, afetivo, social, sobrecarrega os familiares, principalmente se os mesmos não tiverem algum tipo de apoio - pessoas, instituições, espaços de acolhimento e socialização - que possa lhe ajudar nas dificuldades.

Chamam a atenção, também, as declarações dos entrevistados quanto à ausência e o afastamento da família ampliada diante da situação de um parente em situação de transtorno mental. Alguns familiares não apoiam, não querem saber do familiar adoecido, não ajudam a cuidar. Nesse sentido pode-se questionar: seria o preconceito e/ou o medo a afastar esses familiares de um parente que é "doente mental"? Seria a esquiva de prestar-lhe algum cuidado e/ou a vergonha de ter um familiar nessa situação? Diversos podem ser os motivos, mas a realidade apresentada pelos sujeitos da pesquisa é que muitos familiares se afastam da pessoa em situação de transtorno mental.

Nas entrevistas os cuidadores revelam, ainda, ambiguidades no posicionamento de seus parentes. Informaram que os familiares teriam apresentado, inicialmente, um posicionamento - ou pelo menos uma declaração - de apoio frente às dificuldades na convivência e cuidado com o familiar em situação de transtorno mental. Mas tal iniciativa se deu tão somente enquanto ainda não compreendiam os sintomas da doença. Em seguida, as opiniões/julgamentos eram de tratar-se de "frescura" ou fingimento do familiar em transtorno e acabavam por não cooperar ou até mesmo atrapalhar os familiares que se dedicavam ao cuidado, o que faz com que a questão da sobrecarga seja sentida de modo acentuado:

\begin{abstract}
Se tivesse mais apoio da família acho que ajudaria bastante, porque muitos não reconhecem, muitos pensa assim (...) que não, fulana tá com dengo, fulano quer muita atenção, muita gente não dá! Minha vó não reconhece, minhas tias não reconhecem... porque só sou eu pra mim cuidar dela, só que eu ainda tenho que cuidar da casa, tenho que levar pro médico, aí aqui é pra ela vir na terça e da quinta, mas não dá não porque eu tenho que cuidar da casa, dos remédios. (JOANA, filha)

Pra ajudar é assim, o apoio da família, porque assim minha família, não apoio muito, minha família é mais de complicar, minha família é muito complicada, por ser uma família grande a família dela é cada um da um opinião, minha vó, ela é muito cabulosa, ela quer se intrometer, mas ela não ajuda, ela só atrapalha. (LÍDIA, filha)
\end{abstract}

Conviver e cuidar de uma pessoa acarreta, neste contexto, mudanças na vida dos familiares, principalmente no que se refere àquele que é o cuidador principal, com quem geralmente estão as maiores responsabilidades. Esses familiares precisam, desse modo, de apoio que possa lhes ajudar nessa tarefa de cuidado. A maioria dos entrevistados eram cuidadores principais e do sexo feminino e podemos considerar que a mulher desempenha papel central no cuidado ao familiar em situação de transtorno mental, sejam elas mães, 
esposas, filhas. Conforme Rosa (2003) há uma feminização do encargo de cuidar do portador de transtorno mental, demonstrando assim que a questão do cuidado aos familiares passa por uma questão de gênero, onde se vê a mulher como tendo essa função de cuidadora de familiares em situação de adoecimento ou não.

Além de cuidar do familiar adoecido, a maioria das mulheres fica encarregada de cuidar da casa, dos filhos, entre outras funções. A situação de sobrecarga pode ser amenizada quando o cuidador pode dividir com outra pessoa suas atribuições no dia a dia. Entretanto, muitos entrevistados revelam não contar com ninguém para compartilhar o cuidado ao familiar, sobrecarregando somente um ou dois familiares mais próximos. Tal desabafo se expressa em algumas entrevistas:

\footnotetext{
Não mulher, porque ela é assim (...) ela não conta com ninguém, só conta comigo, ela não é menina de você chegar e dizer vamo ali, Ana? Ela não vai, aí só comigo, só comigo! (CÍCERA, mãe)

É como diz, ele não tem apoio de família, a família dele é muito distante, e só quem cuida dele mesmo sou eu, que tenho paciência, que tento ter paciência pra cuidar dele, e a família não é aquela família que alevanta seu astral, já que não cuida (...) (LUIZA, esposa)
}

Alguns familiares afirmam que recebem apoio, mas somente da família nuclear, geralmente daqueles que moram na mesma casa. Outros familiares ainda referiram o Centro de Atenção Psicossocial (CAPS) como apoio e o benefício que o familiar em situação de transtorno recebe - esse benefício faz parte do Programa de Volta pra Casa, que consiste no pagamento mensal de um auxílio-reabilitação no valor de $\mathrm{R} \$ 240,00$ à pessoa egressa de Hospital Psiquiátrico que tenha indicação para a inclusão em programa de reintegração social (BRASIL, 2005). O que corrobora com Santin e Klafke (2011, p.156) quando afirmam que: "O que se ouve com bastante frequência é a sensação de solidão por parte dos familiares em relação ao provimento de cuidado com o seu ente que adoeceu [...] não podem contar com a sua família ampliada ou com vizinhos, sendo o CAPS o único suporte fora da família nuclear”. Eis alguns depoimentos em relação ao apoio que os familiares recebem:

Apoio só dos de casa mesmo, a família imediata meu marido e meus filhos, os irmãos outros nem sequer ligam (...). Uma vez na vida e outra lá no funeral! (GILDA, irmã)

Pra cuidar dela o apoio que eu recebo, são dois no caso, é o apoio aqui do CAPS, que pra mim ta sendo ótimo, quando ela fica aqui. É do CAPS e esse benefício que foi um apoio enorme, porque tinha o remédio dela, o exame que era caro, e meu pai... assim, ele não tem essa estrutura porque ele paga aluguel, aí não tinha como, muitas vezes ela adoecia, aí não tinha como comprar o remédio. (JOANA, filha) 
Nesse sentido é possível considerar que os familiares podem se sentir desamparados em terem que cuidar sozinhos do seu familiar, principalmente quando não recebem o apoio da família ou da comunidade, da rede social mais próxima. Segundo Santin e Klafe (2011, p.55):

\begin{abstract}
Para amenizar a sobrecarga familiar e alcançar o cuidado em saúde mental como preconizado pela Reforma Psiquiátrica, é necessário que se construa uma rede de cuidados, não deixando o indivíduo somente como responsabilidade da família ou dos serviços de saúde, mas integrando todas as estratégias possíveis para atendê-lo de forma integral e humanizada.
\end{abstract}

De acordo com o Ministério da Saúde (BRASIL, 2010), quando se refere ao novo modelo de atenção à saúde mental, a partir da reforma psiquiátrica, a atenção hospitalar deve deixar de ser o centro das ações em saúde mental para se tornar complementar. Na nova forma de cuidado, o mesmo deve ser mais próximo da rede social, cultural e familiar do paciente. Assim, a Política Nacional de Saúde Mental tem como meta a redução gradativa de leitos nos hospitais psiquiátricos, com enfoque na desinstitucionalização, enquanto prioriza a implementação de uma rede de serviços à saúde mental de base comunitária, capaz de atender os pacientes que precisem de cuidados.

\begin{abstract}
A rede de saúde mental, segundo essa perspectiva, deve ser composta de diversas ações e serviços de saúde mental: ações de saúde mental na Atenção Primária, Centros de Atenção Psicossocial (Caps), ambulatórios, residências terapêuticas, leitos de atenção integral em saúde mental (em Caps III e hospital geral), programa de Volta pra Casa, cooperativas de trabalho e geração de renda, centros de convivência e cultura, entre outros. (BRASIL, 2010).
\end{abstract}

Nas entrevistas com os familiares, contudo, o CAPS é o único serviço que a família faz referência e que conhece e conta para o cuidado ao familiar em situação de transtorno mental. Pode-se considerar que na realidade dos familiares entrevistados, a rede de serviços de atenção à saúde mental conta com um CAPS II ${ }^{1}$ (onde foi feita a pesquisa), um CAPS $\mathrm{AD}^{2}$ e um Hospital Psiquiátrico. No contexto desta pesquisa, o CAPS acaba sendo a única referência de cuidado para os familiares como alternativa à não-internação do familiar no Hospital Psiquiátrico, ficando tal instituição sobrecarregada frente à procura desse serviço para atender pessoas em situação de transtorno mental. Diante dessa realidade, cabe

\footnotetext{
${ }^{1}$ CAPS II são serviços de médio porte, e dão cobertura a municípios com mais de 50.000 habitantes. A clientela típica destes serviços é de adultos com transtornos mentais severos e persistentes. Os CAPS II têm capacidade para o acompanhamento de cerca de 360 pessoas por mês. Funcionam durante os cinco dias úteis da semana (BRASIL, 2005).

${ }^{2}$ Os CAPS AD, especializados no atendimento de pessoas que fazem uso prejudicial de álcool e outras drogas previstos para cidades com mais de 200.000 habitantes, ou cidades que, por sua localização geográfica ou cenários epidemiológicos importantes, necessitem deste serviço para dar resposta efetiva às demandas de saúde mental. Funcionam durante os cinco dias úteis da semana, e têm capacidade para realizar o acompanhamento de cerca de 240 pessoas por mês (BRASIL, 2005).
} 
questionar-se: esse novo modelo de cuidado tendo o CAPS como único dispositivo de cuidado alternativo à internação não continua por reforçar a lógica do cuidado separado, excludente, ao "doente mental", sendo o mesmo cuidado em um lugar específico, que agora não é mais o hospital psiquiátrico?

A atenção à saúde mental deve ser oferecida no território do paciente - eis uma das diretrizes da Política Nacional de Saúde Mental - no entanto o CAPS, como único dispositivo de cuidado, muitas vezes fica afastado daquele que seria o território da pessoa em situação de transtorno mental, tendo o familiar que se deslocar, e muitas vezes esse deslocamento não é pequeno para chegar ao CAPS.

Diante do exposto pode-se inferir que mesmo sendo o CAPS um dos principais serviços substitutivos na assistência em saúde mental, ele sozinho não é suficiente para a assistência que o familiar em situação de transtorno mental e sua família precisam ter. Sendo a rede de saúde mental composta de diversas ações (como as ações de saúde mental na Atenção Primária), caso estas se efetivassem na prática, facilitariam um cuidado mais próximo do usuário e de sua família, atendendo às suas dificuldades e necessidades, a partir da lógica do cuidado integral.

\section{3 - A assistência em saúde e a importância de cuidar também da família:}

Os Centros de Atenção Psicossocial (CAPS) representam um serviço de assistência à saúde mental criado para ser substitutivo às internações em hospitais psiquiátricos das pessoas em situação de transtorno mental. O mesmo é um serviço pertencente ao Sistema Único de Saúde (SUS), sendo um lugar de referência, de cuidado intensivo, comunitário, promotor de vida, para pessoas com transtornos mentais, neuroses graves, psicoses, entre outros quadros (BRASIL, 2004). "O objetivo dos CAPS é oferecer atendimento à população de sua abrangência, realizando o acompanhamento clínico e a reinserção social dos usuários pelo acesso ao trabalho, lazer, exercício dos direitos civis e fortalecimento dos laços familiares e comunitários" (BRASIL, 2004, p. 13).

Pelos relatos dos familiares é possível considerar que o CAPS se apresenta como um serviço essencial para auxiliar os mesmos no cuidado à pessoa em situação de transtorno, sendo o único serviço da assistência em saúde mental que os familiares fazem menção e que os ajuda a cuidar e a manter o familiar fora do hospital. Eis alguns depoimentos:

A minha felicidade é o CAPS, porque se não fosse o CAPS ele vivia internado na P., e é uma dificuldade muito triste botar o paciente da gente ali dentro da P., a gente bota quando não pode mesmo, já bota quando eu penso assim né que eu vou ficar 
igual a ele, de lutar com ele, aí o jeito é botar, porque eu não aguento, mas o CAPS é a felicidade da gente (FLORA, esposa).

Em tudo que ela ta aqui (CAPS) isso pra mim é a maior benção de Deus a maior coisa boa do mundo é ela ta aqui, porque aqui ela ta tendo uma boa conversa, uma boa palestra, um bom acompanhamento pra ela, ótimo, ajuda sim. (LÚCIA, mãe).

Pode-se inferir que o CAPS cumpre o seu papel quando se trata da diminuição das internações psiquiátricas das pessoas em situação de transtorno mental, bem como responde positivamente ao cuidado dos pacientes e familiares. Os sujeitos, tanto nas entrevistas quanto na roda de conversa, relatam a atenção e o cuidado que a pessoa em situação de transtorno tem no CAPS, referindo-se ao acompanhamento médico, à medicação que muitas vezes é fornecida. Alguns familiares fazem menção ainda às atividades terapêuticas desenvolvidas nesse espaço, quando se referem à "palestra", "reunião", considerando-as importantes para o tratamento, apresentando a compreensão de que não apenas o acompanhamento médico e o uso da medicação auxiliam a pessoa em situação de transtorno, demonstrando uma visão do tratamento como algo mais amplo, que abrange o bem estar psíquico e social, que passa pela orientação quanto a condutas mais saudáveis, à busca de recursos para manter a saúde, entre outras. Segundo Pereira (2003, p.73):

A construção desse modelo de assistência tem causado profundos efeitos na sociedade atual, pois implica mudança cultural da instituição, dos usuários, dos profissionais de saúde, da família e da comunidade. Dessa forma, não se visa somente tratar de uma doença, mas também à promoção da saúde mental, à adaptação do sujeito à sua realidade.

Os familiares declaram que o CAPS tem os ajudado a ficarem: "com menos peso pra carregar", ou que "A pessoa que cuidar dele, fica mais calma”, e através destes e outros relatos, fica clara a necessidade de atenção e suporte da família para cuidar da pessoa em situação de transtorno e lidar com os desdobramentos próprios desse contexto. Percebe-se que os familiares se sentem aliviados, mais tranquilos, quando contam com algum auxílio no cuidado ao familiar e a si mesmo, que como vimos não é uma tarefa fácil e apresenta dificuldades e sobrecarregas. Para Pegoraro e Caldana (2008), somente a presença da sobrecarga já aponta a família como merecedora de atenção dos serviços de saúde mental para ajudá-la a enfrentar suas dificuldades. Para Santin e Klafke (2011 p.155):

Ajudar os familiares na interação e na gestão da vida cotidiana dos pacientes alivia o peso dos encargos, facilita o processo de estabelecimento de uma cooperação, diminui os fatores estressantes ativadores de situações de crise, estimula a criação de possibilidades participativas, melhorando a qualidade de vida de todas as pessoas envolvidas.

Durante a pesquisa os familiares também se referem ao uso da medicação pela pessoa em situação de transtorno como o que possibilitou os cuidados em casa, uma vez que sem a 
medicação isso não seria possível. Sabe-se que a medicação auxilia na diminuição dos sintomas, auxilia a evitar as crises, etc., sendo essencial no tratamento e, por vezes, a necessidade é inclusive de uso intermitente. Segundo Koga e Fugerato (2002), pela experiência dos familiares os psicofármacos auxiliam na saída das crises da pessoa em situação de transtorno mental, ajudam a solucionar o problema e a maioria dos familiares procura o médico em busca da prescrição de medicamentos quando o familiar piora. Nesse sentido, afirmam esses autores que sem os psicofármacos a desinstitucionalização não seria possível e nem mesmo se ousaria falar nela. Eis alguns depoimentos dos familiares sobre as mudanças a partir do uso da medicação por seus familiares:

\begin{abstract}
Quando ela não tomava os remédios, eu não cuidava, não tinha condições de eu cuidar, porque ela não queria me ver dentro de casa, tinha ódio a mim, e agora não... ela toma o medicamento, ela dorme, come pouquinho mais come, agora tá melhor, eu converso com ela, às vezes brigo com ela, se eu brigar com ela, ela fica chorando, o povo diz tenha paciência, tenha paciência, aí ficou melhor depois do medicamento, só que tem tempo que ela fica aperriada. (CÍCERA, mãe)
\end{abstract}

O CAPS (...) assim (...) acompanha muito ele, é muito bom aqui, já teve assim muita assim né, muita paz dentro de casa, que ele toma o medicamento certo né! (FLORA, esposa)

Os familiares relatam perceber a melhora do seu familiar a partir do tratamento oferecido no CAPS, do uso da medicação e a própria família parece, aos poucos, ir compreendendo melhor o transtorno mental do seu familiar, o tratamento, a partir da aproximação com esse serviço, e das informações que recebe do mesmo, ainda que os desconhecimentos e as poucas informações preponderem em suas realidades. É essencial que a família saiba que pode contar com os serviços de assistência em saúde mental para cuidar do familiar em situação de transtorno, não só no sentido da assistência ao usuário, mas também sendo ouvida em suas dificuldades, recebendo suporte nos momentos de crise do familiar, recebendo também informações e esclarecimento sobre o transtorno, o tratamento, sendo orientada de como lidar com as dificuldades em casa, entre outras.

Segundo os depoimentos dos familiares, o CAPS tem cumprido o seu papel auxiliando a família a melhor entender o transtorno, a deixar o paciente mais calmo, a conscientiza-lo quanto à importância do uso da medicação, além de orientar também os familiares na maneira de como lidar com a pessoa em situação de transtorno mental e ajudar no tratamento e autonomia da mesma. Como se pode observar nessas falas:

Porque aqui [CAPS] a gente vai vendo como é tudo né e foi a menina de lá da P. que mandou trazer ela pra aqui, E eu acho que ela ta outra Jaqueline, ta mais calma, ta consciente que tem que tomar o medicamento. (LÚCIA, mãe) 
Eu acho muito bom, muito bom mesmo, porque assim eu tinha mais cuidado nela, ficava com medo de tudo, como ela era muito agitada, ficava muito nervosa com muita gente, aí eu queria ta perto, muitas vezes eu vinha aqui ela ficava de um lado e eu do outro, porque ela passava mal, porque ela fica calada lá passando mal e não conta a ninguém! Muitas vezes eu pensava... E se ela passar mal? Aí tava do lado, aí a menina foi dizendo: olhe pra ela ir melhorando, pra ela se sentir melhor você tem que ficar mais afastada! Só que quando ela sente alguma coisa ela não fala, ela segura pra ela, aí ajudou muito porque eu queria proteger mais do que devia. (JOANA, filha)

É possível perceber que os suportes recebidos pelos familiares são fundamentais para a manutenção do cuidado destes ao seu familiar e, por consequência, do cuidado a si mesmo. No entanto o contato com a família pelos serviços de atenção à saúde mental não deve se realizar apenas de modo coadjuvante no tratamento. É preciso olhar para o familiar como alguém que também precisa de cuidados. Segundo Santin e Klafke (2011, p.158):

\begin{abstract}
$\mathrm{O}$ trabalho com as famílias requer o estabelecimento de relações de cuidado com o cuidador e não apenas a relação com o familiar no papel de familiar, isto é, uma relação que se volta para ouvir como esta pessoa se sente e como está sendo para ela cuidar e conviver numa família, onde há a presença de muito sofrimento psíquico, e não apenas trabalhar questões de como esta pessoa pode ajudar o seu familiar, o que deve fazer ou não fazer para que ele melhore.
\end{abstract}

Como se vê, a situação de transtorno mental de um membro da família tem ressonâncias na vida dos familiares, principalmente daqueles que se dedicam a cuidar da pessoa em situação de transtorno, e acaba não podendo ou não conseguindo cuidar de si, para prestar assistência ao outro. Diante desse contexto é possível indagar: os serviços de saúde mental têm considerado as ressonâncias na vida dos familiares? Têm levado em conta os impactos provenientes da convivência e cuidado à pessoa em transtorno? A assistência em saúde mental tem, enfim, cuidado da família? Os entrevistados nos seus relatos dão pistas da sobrecarga, do cansaço que sentem na tarefa de cuidar permanentemente de um familiar em situação de transtorno mental e da necessidade de serem também olhados e cuidados, como pode ser observado em suas narrativas:

Quando você tá cuidando de um doente que tá acamado, você se atenta tanto ao doente que tá acamado, que se esquece da pessoa que tá cuidando do acamado e que não tá dormindo bem a noite (...). Ele não tá se alimentando bem, ele não tá descansando bem, mas a atenção dos vizinhos, a atenção dos amigos, a atenção é voltado pra aquele que tá acamado e esquece de quem tá cuidando, então isso eu ainda acho que é muito carente. (GILDA, irmã)

Quando eles passa pra falar você tem que ouvir viu, na hora que eles passa pra falar em casa você tem que pensar e ter temperamento, ultimamente eu vou lhe dizer, o tempo vai, tempo vem, a gente vai levando, vai se cansando, vai se cansando, muitas vezes você não tá muito pra ouvir, muitas vezes quem tá precisando de um psicólogo é você, num é nem ele que tá tanto precisando, é nós, que tamo precisando (JOÃO, esposo) 
Apesar de relatarem o auxílio que recebem do CAPS no cuidado ao seu familiar, os familiares denunciam a falta de uma atenção mais específica à família, demandando uma escuta desses serviços às suas dificuldades, ao seu dia a dia, de maneira a poder serem também ajudados. Os familiares vão apontando, assim, as brechas, carências e ineficiências dos serviços da assistência à saúde mental. Eis alguns dos seus depoimentos:

O fato de estarem me ajudando com ele já é alguma coisa, é uma metade e a outra metade infelizmente ainda é carente. Mas eu sei que o intuito do serviço é esse é cuidar dos dois lados, mas a demanda é tão grande nesse serviço, é um serviço novo, até porque só tem dois CAPS na cidade que eu saiba, então a demanda é muito grande, mas eu tô satisfeita com o serviço. Mas tem me ajudado muito em relação a ele, com ele. Mas ainda é deficiente em relação a família. (GILDA, irmã)

Devia ter um psicólogo para os familiares, aqui dentro do (...). Tinha que ter, não é assim esse monte de gente não, era pra atender cada pessoa, ter aquele... por exemplo, duas hora ou uma hora, pra atender cada familiar, um parente, um pai, uma mãe, um irmão, um tio, uma tia, entendeu? Ter que passar pelo psicólogo pra o psicólogo saber o que é que ele tá passando, o que é que acontece dentro de casa entendeu? E ele ser orientado pela essa pessoa, pelo psicólogo, isso deveria ter aqui, isso é uma boa ideia pra o grupo de família. (CLÁUDIO, esposo)

É possível perceber a dificuldade dos serviços de atenção à saúde mental em voltarem o seu olhar e ação para o cuidado também à família. Os próprios familiares vão apontando as razões dessa dificuldade: devido à grande demanda ao serviço e aos poucos recursos do mesmo. No entanto, sabe-se que é imprescindível que os serviços que acompanham a pessoa em transtorno estejam também atentos à família em suas dificuldades, seus sofrimentos. Para ter condições de cuidar, é essencial o bem-estar e a saúde do cuidador e em seus depoimentos eles deixam claro não acessar qualquer outro espaço de atenção para si. Daí nossa questão: como os familiares têm cuidado de si? O que têm feito para manter a sua saúde, para se divertir, relaxar, etc.? Quais são as estratégias que desenvolvem, em seu cotidiano, em prol de seu bem-estar e do equilíbrio da dinâmica familiar? Eis algumas respostas:

A diversão é em casa mesmo, eu ligo minha televisão, ligo meu DVD, escuto uma música, assisto um filme, essa é a minha diversão, eu não saio pra canto nenhum, eu não gosto de festa, eu não gosto de... a não ser sair pra ir no parque, dar uma caminhada, fazer uma caminhada, eu levo até ela comigo, mas eu tiro um tempo tanto pra mim quanto pra ela. (CLÁUDIO, esposo)

Eu só vou pra numa festa (...). Assim festival de inverno, foi nos três umas três noites nós fumo, e não bebe, mas toma um chocolate quente e depois nós vem simbora, sempre eu dou a preferência minha a eles porque pra eu sair sozinho pra eu me divertir e elas ficar em casa eu sei que fica faltando alguma coisa. (ARNALDO, esposo).

Pelos depoimentos dos familiares percebe-se que o cuidado de si ainda está muito atrelado ao cuidado do outro, de maneira que os familiares parecem não conseguir pensar em si sem pensar no familiar que está adoentado. Os familiares parecem firmar um compromisso em que o seu bem-estar passa pelo bem-estar do outro, e só assim conseguem estar tranquilos, 
felizes. Outros familiares, porém, revelam as repercussões nas suas vidas a partir do cuidado ao familiar em situação de transtorno. Alguns afirmam ter adoecido pela sobrecarga do cuidado, relataram a necessidade do uso de psicofármacos e de terapia diante desse contexto. Outros ainda revelam ter abdicado da sua própria vida, dos seus planos para cuidar dos seus familiares. Eis algumas falas ilustrativas:

\footnotetext{
Minha mãe tem depressão, ninguém sabe a hora que ela tá cem por cento e ninguém sabe a hora que ela vai tá zero, aí fica difícil, se eu não tirar um tempo pra fugir daquilo ali eu acho que eu enlouqueço, mas agora eu tô começando a correr atrás da minha vida porque eu não tô vivendo a minha vida, eu tô vivendo a realidade do meu pai e da minha mãe, eu tô querendo arrumar um emprego pra mim, eu tô tentando cuidar de mim, tirar da dependência porque meu pai é muito dependente de mim e minha mãe a mesma coisa (LÍDIA, filha).

E eu adulta e por coincidência também trabalhava como cuidadora, eu ganhava dinheiro pra fazer isso, e inda tinha que tirar horas para ir a casa da minha mãe, cuidar da casa, dar os banhos dela, levar ela a medico, aí eu era cuidadora dela e cuidadora de outras pessoas, no caso dela chegou a hora que eu adoeci, aí eu tive que cuidar de mim, aí você não pode preocupar mais quem vai cuidar, quem vai dar banho, quem vai dar de comer, porque, porque você não pode mais fazer nada, você não tem condição, aí pela primeira vez eu fui a um psiquiatra e comecei tomar fluoxetina, era pouquinha era 10 ainda, mas eu tive que assim... por muito tempo fazer até terapia (TÁSSIA, filha).
}

Podemos constatar a importância do cuidado de si para os familiares que cuidam de alguém em situação de transtorno mental. Muitas vezes esses familiares frente a tantos encargos, compromissos esquecem de olhar para suas próprias vidas. Atentos ao cuidado do outro acabam distanciando de si mesmos, o que contribui para que adoeçam. Alguns familiares só percebem a necessidade de olhar para si a partir do adoecimento, quando precisaram se cuidar, outros em contrapartida se dão conta da necessidade de cuidar da sua vida, cuidar de si, por estar vivendo em função do outro.

Nesse sentido, é essencial que a assistência em saúde mental esteja atenta à saúde do cuidador, dando condições para que o cuidador cuide de si e seja cuidado, oferecendo-lhe suporte que o alivie em suas sobrecargas, acolhendo suas dificuldades, ouvindo seus sofrimentos, angústias e procurando também ajudá-los. É imprescindível, portanto, que os serviços de assistência à saúde mental criem estratégias que contemplem os familiares, buscando garantir o bem-estar e a saúde mental também daqueles que se dedicam ao cuidado.

\section{Considerações Finais:}

Essa pesquisa promove uma reflexão de que já não são toleráveis atitudes de exclusão, estigmatização, preconceitos em relação à pessoa em situação de transtorno mental, bem como que o seu cuidado integral deve incluir tanto a desospitalização quanto a elaboração de 
estratégias eficazes de cuidado e inserção social. Contudo, pode-se compreender que também não é deixando os pacientes sob responsabilidade e cuidados da família que se garante um tratamento psicossocial efetivo. A pesquisa nos revela que a família, muitas vezes, não tem condições psicológicas, físicas, sociais e financeiras para cuidar de um parente em situação de transtorno e acaba sofrendo e até adoecendo em meio a esse contexto. A família precisa de suporte para assumir o lugar de cuidadora, seja de outros membros da família, da rede social ampliada, dos serviços de saúde e, para além disso, precisa ser ouvida e acolhida em seus sofrimentos, angústias e dificuldades, também na rede de assistência pública.

Muitos familiares revelaram durante a pesquisa episódios de sofrimento psíquico, além de enfermidades físicas, adquiridas a partir da situação do transtorno mental do familiar. Não há como negar que a situação de transtorno altera a dinâmica da família, que muitas vezes tenta se adaptar, encontrar formas de lidar com o estresse, com as dificuldades vividas a partir do adoecimento de um de seus membros, mas nem sempre consegue e os familiares acabam adoecendo. É preciso criar intervenções que ajudem os familiares a cuidar da pessoa em situação de transtorno mental, que melhorem a sua qualidade de vida atuando, assim, preventivamente frente à sobrecarga e o estresse mobilizados diante do novo e diante das elevadas demandas requeridas na atitude do cuidar.

A partir dessa pesquisa foi possível, também, identificar como a assistência em saúde mental, que tem o CAPS como a única referência para os familiares desse estudo, os tem auxiliado. Fica evidente, nos relatos, uma evolução clínica dos pacientes em situação de transtorno mental a partir do tratamento no CAPS, este que ajuda também os familiares a lidar com os mesmos. No entanto, as práticas de cuidado e atenção à família não têm se mostrado efetivas, de maneira que os familiares afirmam que a atenção dos serviços acaba ficando restrita à pessoa em situação de transtorno mental e a família, desassistida. Ainda, os participantes afirmam o desconhecimento de outras instituições que atuem como rede de apoio em seu cotidiano, à despeito do que propõem as políticas integrais de saúde e assistência social.

Diante do exposto percebe-se que, no novo modelo de atenção à saúde mental, é imprescindível que os serviços voltem o seu olhar também aos familiares que, como vimos, demandam cuidado e atenção. A reinserção das pessoas em situação de transtorno mental não pode acontecer causando transtornos e sofrimentos à família. É preciso que se busquem alternativas, estratégias e contemplem ações também direcionadas à família, e à promoção de seu bem-estar e saúde. 
Sem a pretensão de dar a temática por encerrada, espera-se que esta pesquisa traga a reflexão sobre a importância do cuidado ao cuidador pelos serviços de assistência à saúde mental e que isso repercuta em mudanças nos modos de pensar a família cuidadora, transformando-a de coadjuvante a personagem principal, junto aos pacientes, nos serviços públicos de saúde mental.

\title{
A LOOK TO THE FAMILY: PSYCHOLOGICAL RESONANCES IN RELATIVES LIVING WITH A PERSON IN A MENTAL DISORDER SITUATION
}

\begin{abstract}
:
Mental disorders are characterized by changes in behavior, mood and way of thinking, which may cause functional impairments, not only leading to suffering to the person who falls ill but also to those who live with, especially to the family that becomes the main caregiver. The research sought to understand psychosocial resonances in family members who live with and look after a relative in mental disorder situation. Therefore, a qualitative study was conducted with the participation of user's families of the Centro de Atenção Psicossocial (CAPS) who attend to the family support group in the institution. This study included semi-structured interviews and conversation circles with users' families. The Content Analysis revealed three categories of discussion, namely: family feelings in front of the mental disorder of its family; the family in acquaintanceship and care to the person with mental disorders situation; the mental health care and the importance of caring for the family as well. Based on the statement of the sufferings, difficulties and implications for their physical and mental health in the context of the disease, it was found the need for attention and assistance to the families who care for a person in mental disorder situation. The CAPS has had its performance positively recognized by the family of its users, even though they contain restricted spaces and support networks and limited action with regard to the completeness and reception to the family.
\end{abstract}

Keywords: Mental disorders; Family; Care.

\section{UNA MIRADA A LA FAMILIA: RESONANCIAS PSICOSOCIALES EN FAMILIARES QUE CONVIVEN CON UNA PERSONA EN SITUACIÓN DE TRASTORNO MENTAL}

\section{Resumen:}

Los trastornos mentales se caracterizan por alteraciones en el comportamiento, en el humor y en la manera de pensar, pudiendo causar comprometimientos funcionales, provocando sofrimientos no solo a la persona que se enferma, mas a las personas con quien ella convive, en especial a la familia que se torna la cuidadora principal. La pesquisa buscó comprender resonancias psicosociales en familiares que conviven y cuidan de un pariente en situación de trastorno mental. Para tanto, se realizó una pesquisa cualitativa, que incluyó entrevistas semiestructuradas y ruedas de conversación junto a familiares de usuarios de un Cientro de Atención Psicosocial (CAPS), que frecuentan el grupo de apoyo familiar en la institución. La Análisis de Contenido reveló tres categorías de discusión, a saber: sentimientos de la familia delante del trastorno mental de su familiar; la familia en la convivencia y cuidado a la persona en situación de trastorno mental; la asistencia en salud mental y la importancia de cuidar 
también de la familia. Se constató la necesidad de atención y asistencia a los familiares que cuidan de una persona en situación de trastorno mental, a partir da constatación de los sofrimientos, dificultades y implicaciones en su salud física y mental frente al contexto de la enfermidad. Aunque los familiares cuenten con restrictos espacios y redes de apoyo y que, a pesar de una accíon limitada en lo que se refiere a la integridad y acogimiento al familiar, el CAPS viene teniendo su actuación reconocida positivamente por los familiares de sus usuarios.

Palabras-clave: Transtornos mentales; Familia; Cuidado.

\section{Referências}

BARDIN, Laurence. Análise de Conteúdo. Lisboa: Edições 70, 1977.

BORBA, L. D. O. et al. A família e o portador de transtorno mental: dinâmica e sua relação familiar. Revista Escola de Enfermagem da USP. São Paulo, v. 45, n.2, p. 442-449, 2011.

BORBA, L. O.; SCHWARTZ, E.; KANTORSKI, L. P. A sobrecarga da família que convive com a realidade do transtorno mental. Acta Paulista Enfermagem. São Paulo, v. 21, n.4, p. 588-94, 2008.

BRASIL. Ministério da Saúde. Secretaria de Atenção à Saúde. Saúde mental no SUS: os centros de atenção psicossocial. Brasília, DF, 2004.

Ministério da Saúde. Secretaria de Atenção à Saúde. Reforma psiquiátrica e política de saúde mental no Brasil. Brasília, DF, 2005.

Ministério da Saúde. Secretaria de Atenção à Saúde. Diretrizes do NASF: Núcleo de Apoio a Saúde da Família. Brasília, DF, 2010.

CAVALHERI, S. C. Transformações do modelo assistencial em saúde mental e seu impacto na família. Revista Brasileira de Enfermagem. Campinas, SP, vol.63, n.1, p. 51-57, 2010.

COLVERO, L. D. A.; IDE, C. A. C.; ROLIM, M. A. Família e doença mental: a difícil convivência com a diferença. Revista Escola de Enfermagem da USP. São Paulo, v.38, n.2, p.197-205, 2004.

FABRIS, D. R.; YKEGAYA, T. R. Da Loucura ao Transtorno mental: a constituição de políticas sociais e seus pressupostos. Tempo da Ciência. Paraná, v. 18, n.35, p 137-151, 2011.

FIGUEIRÊDO, A. A. F.; QUEIROZ, T. N. A utilização das rodas de conversa como metodologia que possibilita o diálogo. In: SEMINÁRIO INTERNACIONAL FAZENDO GÊNERO, 10, Anais Eletrônicos. Florianópolis, 2012. p. 1-10.

FOUCAULT, MICHEL. História de Loucura: na idade clássica. São Paulo: Perspectiva, 2007. 
KOGA, M.; FUREGATO, A. R. Convivência com a pessoa esquizofrênica: sobrecarga familiar. Revista Ciência cuidado e saúde. Maringá, v.1, n.1, p.69-73, 2002.

MELMAN, Jonas. Família e doença mental: repensando a relação entre profissionais de saúde e familiares. São Paulo: Escrituras Editora, 2006.

MINAYO, M. C. D. S. Pesquisa social: teoria, método e criatividade. 27. Ed. Petrópolis: Vozes, 2008.

NARVARINI, V.; HIRDES, A. A família do portador de transtorno mental: identificando recursos adaptativos. Texto e Contexto de Enfermagem. Florianópolis, v.17, n.4, p. 680-8, 2008.

PEGORARO, R. F.; CALDANA, R. H. L. Sofrimento psíquico em familiares de usuários de um Centro de Atenção Psicossocial (CAPS). Interface- Comunicação, saúde, educação, Botucatu, v.12, n.25, p. 295-307, 2008.

PEREIRA, M. A. O. Representação da doença mental pela família do paciente. InterfaceComunicação, saúde, educação. Botucatu, v. 7, n. 12, p.71-82, 2003.

ROSA, Lúcia. Transtorno Mental e o cuidado na família. São Paulo: Cortez, 2003.

SANTIN, G.; KLAFKE, T. E. A família e o cuidado em saúde mental. Barbarói, Santa Cruz do Sul, n. 34, p. 146-160, 2011.

SANTOS, É. G. D.; SIQUEIRA, M. M. D. Prevalência dos transtornos mentais na população adulta brasileira: uma revisão sistemática de 1997 a 2009. Jornal Brasileiro de Psiquiatria, Rio de Janeiro, v. 59, n. 3, p. 238-246, 2010.

SOARES, C. B.; MUNARI, D. B. Considerações acerca da sobrecarga em familiares de pessoas com transtornos mentais. Ciência Cuidado e Saúde, Maringá, v.6, n.3, p. 357-362, 2007.

SPADINI, L. S.; SOUZA. M. C. B. M. A doença mental sob o olhar de pacientes e familiares. Revista da Escola de Enfermagem da USP, São Paulo, v.40, n.1, p. 123-7, 2006.

Data de recebimento: 28/09/2013.

Data de aceite: $01 / 11 / 2017$.

\section{Sobre as autoras:}

Maria Helena Santos Almeida é Mestranda em Programa de Mestrado Profissional Práticas e Inovações em Saúde Mental-Universidade de Pernambuco- Campus Garanhuns. Endereço Eletrônico: mariahelena_lenninha@ hotmail.com

Érika de Souza Mendonça é Doutoranda, Professora Adjunta da Universidade de Pernambuco

- Campus Garanhuns. Endereço Eletrônico: erika.mendonca@ hotmail.com 